\title{
Performance religiosa e mobilidade social de mulheres no Portugal dos séculos XVII e XVIII
}

Religious Performance and Social Mobility of Women in Seventeenth and Eighteenth-century Portugal

\author{
Lígia Bellini* \\ Moreno Laborda Pacheco** 1
}

Resumo

$\mathrm{O}$ artigo examina trajetórias de mulheres que, no Portugal dos séculos XVII e XVIII, alcançaram certa distinção social a despeito de seu pertencimento a setores subalternos, no que se refere especificamente a hierarquias de gênero ou origem social. A análise funda-se em processos do Santo Ofício relativos aos crimes de molinosismo e fingimento de êxtases, visões e revelações, em livros de fundação de conventos, e em tratados voltados para a discussão de assuntos morais e vidas santas. As táticas e competências de que as mulheres enfocadas lançaram mão para alcançar posições ou papéis distintos dos originalmente destinados a elas não se relacionam à linhagem, à administração do reino ou às atividades econômicas de prestígio, mas à performance religiosa. Entretanto, observam-se homologias entre as ideias enunciadas para descrever e/ou validar os casos aqui estudados e as categorias

\section{Abstract}

This article deals with the paths of a number of women who achieved a certain social distinction in seventeenth and eighteenth-century Portugal, despite the fact that they belonged to lower strata with respect to gender or social origins. The analysis is based on Inquisition proceedings related to the crimes of molinosism and simulation of ecstasies, visions and revelations; on written memories of religious communities; and on treatises about moral themes and saintly lives. The tactics and competences that enabled these women to reach such positions are not related to lineage, to the kingdom's administration or to prestigious economic activities, but to religious performance. Notwithstanding the particular characteristics of the cases examined here, there are homologies between the conceptions used to describe and validate them and the ones that re-

\footnotetext{
* Universidade Federal da Bahia (UFBA), Programa de Pós-Graduação em História. Salvador, BA, Brasil. ligiabellini@uol.com.br

** Universidade Federal da Bahia (UFBA), Departamento de História. Salvador, BA, Brasil. morenopacheco@gmail.com
} 
associadas a processos mais institucionalizados nas instâncias jurídica e de governo.

Palavras-chave: mulher; mobilidade social; religiosidade no Portugal moderno. fer to more institutionalized processes in the domains of law and government. Keywords: woman; social mobility; religious practices in modern Portugal.

A historiografia dedicada ao estudo da estruturação, reprodução e mudança das hierarquias sociais no Portugal moderno faz menção a um conjunto de categorias utilizadas para designar as camadas intermédias e os processos dos quais resultou sua constituição. Essas investigações em geral contemplam estratégias de ascensão e distinção social associadas à estratificação estamental, às atividades produtivas de prestígio ou à ocupação de posições de governança. Propõe-se discutir, neste artigo, trajetórias de mulheres no domínio religioso português que lhes facultaram ocupar lugares de certo destaque nas comunidades em que atuaram, muitas vezes a despeito de seu pertencimento a setores subalternos, no que se refere especificamente a hierarquias de ordem ou gênero. A costura de um espaço de atuação que as lançasse para além de posições ou papéis originalmente destinados a elas envolveu habilidades e competências outras que não as tradicionalmente ligadas ao sangue, à administração do reino ou ao acúmulo de riqueza. Suas rotas de aquisição de prestígio e destaque foram elaboradas em campos relacionados à performance religiosa.

Utiliza-se aqui o termo performance em sua ampla gama de significados - desempenho, atuação, ação planejada -, inclusive em uma acepção relacionada com a ideia de encenação. As diversas interpretações dos fenômenos abordados na historiografia, brevemente citadas adiante, aproximam-se mais de uma ou outra das conotações do termo. No entanto, independentemente de como as trajetórias e ações referidas na documentação tenham sido tratadas pela instituição eclesiástica e de como as interpretemos, parece indiscutível que constituem fenômenos do campo da religiosidade e que contribuíram para que essas mulheres adquirissem relativo prestígio. Nossa ênfase recai mais na perspectiva de uma história social do que na discussão de questões predominantes do ponto de vista da história religiosa, entendida em sentido estrito.

A noção de mediania, expressa em tratados de análise política, escritos jurídicos ou reflexões genéricas sobre os grupos que compunham a sociedade, conheceu uma difusão significativa ao longo dos séculos XVII e XVIII (Durães, 2013, p.319). Essa difusão é normalmente associada, por um lado, à própria complexificação e diferenciação social, com a ampliação dos estratos terciários 
urbanos, e, por outro, aos esforços de ajustamento conceitual dos parâmetros que explicavam e conduziam essas mesmas transformações. Um "estado do meio" entre a nobreza e o povo mecânico é criado, pela doutrina jurídica, para conferir um estatuto diferenciado aos titulares dessas novas funções civis ou políticas. Ocorre, na formulação de Nuno Gonçalo Monteiro, um "alargamento do conceito de nobreza", possibilitando o ingresso nesse novo estrato "pelo desempenho de funções nobilitantes (pertencer ao corpo de oficiais do exército de primeira linha ou das ordenanças, à magistratura ou simplesmente a uma câmara municipal etc.) ou, negativamente, pelo não exercício de funções mecânicas" (Monteiro, 1998, p.334-336). Além disso, gozariam de uma "quase nobreza" aqueles que "pelo privilégio, e estimação da arte", segundo o tratadista Antonio de Vilas Boas e Sampaio (1629-1701), integravam um estado distinto dos plebeus stricto sensu. Esse é o caso dos pintores, cirurgiões, boticários, escultores, impressores e livreiros, sobretudo os de alguma expressão (Durães, 2013, p.326).

Um aspecto que salta aos olhos na maior parte das discussões sobre espaços intermédios e ascensão social é a ausência das mulheres. Ao tratar de lugares de mulheres de modo geral na Europa moderna, Natalie Zemon Davis afirma que elas encontravam-se mais comumente "nas margens". Estavam relativamente distantes dos centros formais de poder político e religioso, assim como de outras instituições que lhes permitissem exercer ampla influência cultural. Como argumenta Davis, a ideia de "margem" deve ser entendida não como uma zona estéril ou rarefeita, mas sim como "uma região limítrofe entre depósitos culturais que permitiam novos cultivos e híbridos surpreendentes" (Davis, 1997, esp. p.195-196).

Em artigo no qual reflete sobre novos modos de conceber uma história do poder e das elites, António Manuel Hespanha explora a possibilidade de alargamento, nas análises, do que ele designa como planos de emergência desse setor, "com a eventual consequência de trazer para a luz da observação histórica grupos de outro modo subalternos". O caso das mulheres é mencionado tanto no que concerne ao mundo da piedade religiosa mais institucionalizada - tratado pelo autor como parte do conjunto habitual de planos de emergência dos grupos elitários - quanto no que se refere à religiosidade marginal - onde elas estão presentes "em todo o esplendor das suas qualidades femininas, a concitar prestígio, a capitalizar poder e a suscitar obediências e fidelidades" (Hespanha, 2005, p.41-42).

De alguma maneira, os caminhos para o acúmulo de prestígio apontados aqui se afastam das modalidades de categorização e normatização mais 
estreitamente vinculadas ao Estado e se aproximam mais daquelas formas de coesão social que corriam à sua revelia, a exemplo das confrarias ou dos grupos de juventude de que fala Diogo Ramada Curto (1988, p.201-202). Isso não significa dizer que estivessem alheios a mecanismos de controle e coerção, fossem eles de enquadramento jurídico ou simplesmente montados sobre discursos moralizantes. De fato, uma primeira reflexão acerca da ascensão de mulheres a posições de prestígio esbarra em avaliações dos papéis socialmente esperados para elas. Seguindo ainda a formulação de Curto, para além do tema da desigualdade natural entre os homens, constante em discursos do Portugal moderno - "há, entre os homens, estados tão diversos, que se distinguem entre si mais que as espécies dos brutos”, registra a Arte de furtar -, uma análise como a pretendida aqui torna necessário, inicialmente, marcar as fronteiras que separavam homens e mulheres.

\section{EsPaÇOS CONVENCIONAIS DE ATUAÇÃO DAS MULHERES}

Normalmente construídos em torno das ideias de recato, humildade, silêncio e prudência, os comportamentos esperados para as mulheres estão associados a uma perspectiva da natureza feminina considerada essencial para a manutenção do ordenamento natural do mundo, no qual homens e mulheres cumpririam funções desiguais e complementares. Essa ideia é lugar-comum em obras de cunho moralizante produzidas no Portugal dos séculos XVI e XVII, e permanece influente no Setecentos, como demonstra a longevidade editorial da tratadística que discorre sobre o estatuto dos casados e sobre a própria instituição do casamento. Essa tradição literária oferece, aliás, algumas rotas para detectarmos, tendo como orientação a preciosa contribuição de Maria de Lurdes Correia Fernandes sobre a matéria, ${ }^{2}$ os pensamentos acerca das diferenças entre gêneros no período. A exiguidade do espaço de que dispomos permite apenas que apresentemos, aqui, uma visão de conjunto dessas concepções por meio de exemplos, sem contextualizarmos histórica e culturalmente as particularidades dos autores citados. ${ }^{3}$

Para João de Barros, no Espelho de Casados (1540), o "governo" da casa dependia tanto de um como de outro, mas ao homem cabia "Negoçear. Tractar. Ganhar. Defẽder. Demãdar. e fazer outras cousas q sõ neçesarias pa mãter sua casa”. À mulher conviria "guardar tudo e mãdar cõçertar sua casa: ter comer: e mesa prestes a seu marido" (Barros, 1540, fls. XXXIIV-XXXIII; Fernandes, 1996, p.80). Anos mais tarde, a harmonia no governo do lar também mereceu a atenção de Diogo de Paiva de Andrade que, em seu Casamento Perfeito, de 
1630, lembra que o equilíbrio ideal só seria atingido com disciplina na divisão das tarefas. Para atingir a perfeição, o homem deveria ocupar o seu lugar como "a principal parte do governo", mas as mulheres jamais deveriam ser excluídas a ponto de ficarem "em grao igual com os criados". Em verdade, prossegue Andrade, certas tarefas pertenceriam tanto a elas que, se os maridos as governassem, seria "muito grande defeito seu, \& muito mayor desgoverno da casa". A repartição se dá como em João de Barros: "a elles dà os negocios das portas a fóra, \& a ellas os das portas a dentro" (Andrade, 1630, p.54-55).

"Os maridos que em tudo querem mandar são dignos de reprensão, igualmente aos que não querem mandar em nada", afirma Francisco Manuel de Melo em sua Carta de guia de casados, de 1651, compactuando com a ideia de que a manutenção da conformidade doméstica dependia da divisão das tarefas. Mas essa partilha deveria ser feita pelo homem - cabeça e esteio do lar -, de modo a liberá-lo das miudezas que desviavam seu pensamento de causas mais importantes. Para as esposas, ao contrário, as pequeninas coisas seriam "muito convenientes". Enfadava-o "umas que se metem em eleições de governos, julgar de brigas, praticar desafios, mover demandas"; e "outras que se prezam de entender versos, abocanham em linguagens alheias, tratam questões de amor e de fineza, decoram perguntas para gentes discretas, trazem memorial de motes dificultozos" (Melo, 1651, p.85, 96). A delimitação das áreas de atuação doméstica, portanto, se comunicava de maneira orgânica com outras esferas da vida social. O recato e a humildade deveriam guiar não apenas o comportamento doméstico, mas também o tipo de educação dispensada a meninas, e limitar o exercício de qualquer tipo de autoridade "portas afora". Controle do ensino e cerceamento da toma da palavra eram dois pontos nevrálgicos e que, naturalmente, andavam juntos. Fazendo uso farto de adágios, Francisco Manuel de Melo cita, a certa altura, o que ouviu de um "chapado recoveiro", que "Deus o guardasse de mula que faz him, e de mulher que sabe latim". Para além do gracejo, Melo aponta que o núcleo da questão não residia no fato de uma mulher ter alcance suficiente para saber o latim, nem no latim em si mesmo, mas naqueles "outros saberetes" que vêm envoltos nele e deslocam a mulher do espaço que deveria ocupar (Melo, 1651, p.95-96). Discordando dos que rebaixavam seu potencial, Melo afirma que, pelo contrário, por "sua agilidade no perceber e discorrer, em que nos fazem ventagens [a 'nós', homens], é necessario temperá-la com grande cautela": "Assi, pois nos não é lícito privarmos as mulheres do sutilíssimo metal de entendimento com que as forjou a natureza, podemos, se quer, desviar-lhe as ocasiões de que o agucem em seu perigo e nosso dano" (Melo, 1651, p.94-95). 
Duarte Nunes de Leão explica a rarefação de mulheres instruídas em Portugal, quando comparada ao que se verificava em outras nações e tempos, pela "honestidade \& vergonha" das portuguesas, pouco afeitas a se mostrarem em público. Mas se a elas fosse permitido ingressarem nas instituições de ensino e "aprenderem como aos homẽs", continua, "não ha duvida senão q fora mui grãde o numero das letradas q poderão meter em cõfusaõ a muitos homẽs q nas scholas aprẽderão muitos annos, e nellas tomarão graos" (Leão, 1610, fl. 151).

As queixas pela ausência do costume de educar as meninas segundo suas reais potencialidades não eram pura retórica. De fato, e apesar da existência destas obras abertamente defensoras do engenho feminino, esses lamentos são sinalizadores do "estado de espírito" detectável à época em que foram escritos, do qual mais representativos seriam os ásperos Martim Afonso de Miranda - que em seu Tempo de Agora destila contra a ociosidade, o perdularismo, a vaidade, a intemperança e a imodéstia das mulheres de seu tempo (Miranda, 1622, fls. 71-73; 111-115v) - ou, como visto, o próprio Francisco Manuel de Melo (Boxer, 1977, p.127-128; Veloso, 1986, p.266-267). Também João de Barros constrói sua caracterização dos vícios da mulher baseando-se no arsenal argumentativo que movia as penas de seus detratores. As quarta e quinta (de um total de 12) razões destiladas contra o casamento, por exemplo, discorrem sobre a "simpleza" das mulheres e sua "inconstãçia", respectivamente, enquanto a nona, um tanto mais intransigente, trata das "tachas e manhas da molher". Encontram lugar nessas páginas argumentos, retirados de autores diversos, em sustentação da subalternidade intrínseca ao gênero feminino; da sua natureza vã e mutante e de sua incapacidade de realizar funções que demandassem competência e probidade; da verborragia que acompanhava sua insensatez inata; e da sua natureza insidiosa e propensa para o mal (Barros, 1540, fls. IXXIV; XVII-X[V]III).

O temor pela toma pública da palavra anda lado a lado com derivações da sabedoria paulina em diversos testemunhos da Época Moderna. Como em Juan Luis Vives, que cita as célebres passagens de Timóteo e dos Coríntios para condenar a vaidade das mulheres que exibem seus conhecimentos: "y quiero que aprenda por saber, no por mostrar alos otros que sabe: porq es bien que calle: y entonces su virtud hablara por ella" (Vives, 1539, fl. Ixv). Ao "docere autem mulieri non permitto" também recorreu um comissário do Santo Ofício espanhol para sacramentar seu parecer desfavorável à publicação de um "librico de doctrina christiana” de Isabel Ortiz, numa apreciação que, antes de fundar seu argumento na matéria tratada ou nos modos de abordá-la (que também foram objeto de impugnação), parece ter se escorado no sexo de sua autora e 
em sua ousadia por buscar, pela imprensa, fazer uso da palavra e acrescentar sua voz num campo reservado aos homens da Igreja. Um dos confessores de Maria de Ágreda, em atitude que não se pode caracterizar como isolada, obrigou-a a destruir todos os seus papéis sob a alegação de que a escrita não era tarefa para uma mulher, "porque ... as mulheres não deviam escrever na santa Igreja” (Castillo Gómez, 1999, p.111; Evangelisti, 2007, p.73-74).

Em estudo acerca do pensamento religioso sobre a mulher, Fernando Taveira da Fonseca cita um sermão que deixa transparecer outras razões pelas quais a palavra feminina deveria ser vista com reservas. Mencionada como "Sermão sobre a vaidade das mulheres" no índice do volume onde está copiada, e provavelmente escrita por um jesuíta entre 1640 e 1673, essa prédica insiste em dois pontos fundamentais: a inconstância das mulheres e sua incapacidade de julgar as coisas com sensato juízo. Para o pregador anônimo, se elas possuíam a faculdade do entendimento, não eram capazes de fazer bom uso dele, já que, dominadas pelos excessos de sentimento, eram naturalmente avessas à razão. Impossibilitadas de examinar mais detidamente o que esta lhes apresentava, teriam comportamentos governados pelas precipitações de suas vontades. Dessa natureza inconstante e vã, lhes nasceria uma "credulidade" que as condenaria a "viverem sempre enganadas ou pelo menos expostas ao engano" (Fonseca, 1986, p.9-12).

A mera possibilidade de exposição ao engano bastava para desconfiar de qualquer palavra feminina. Recorrendo a Gerson, Gaspar Navarro, em seu Tribunal de la superstición ladina, afirma que era preciso atentar para o sexo de quem tivesse revelações: "es à saber, si es muger, ò hombre; porque caeteris paribus, mas credito se ha de dar á las revelaciones del hombre, que de la muger; porque este sexo femineo es mas flaco de cabeça; y las cosas naturales, ò ilusiones del Demonio las tienen por del Cielo, y de Dios; sueñan mas que los hombres, y piensan que son verdades apuradas". Navarro segue indicando que, como as mulheres têm menos juízo e prudência, elas se tornavam o alvo predileto do demônio, que as ludibriava por meio de falsas imaginações, revelações e visões. O problema se agravaria na medida em que fossem essas mulheres "distraydas, habladoras, locas, amigas de enseñar, y predicar à los demas", e as ilusões seduzissem terceiros. Em especial, os "hombres muy doctos, y cuerdos" que a essas opiniões dessem crédito (Navarro, 1631, fls. 32-32v; Vives, 1539, fl. X).

Por razões parecidas, Juan Luis Vives via com maus olhos que mulheres alcançassem a condição de mestras. Derivava também daí o sentimento de que o exercício do poder por mulheres era subversivo (King, 1991, p.159-160). Se as mulheres eram mais suscetíveis à ilusão, sua propensão de sucumbir diante 
de impulsos interiores também podia causar inversões no plano exterior: “o inferior controlava o superior no interior da mulher e, se fizesse o que queria, ela iria querer controlar seus superiores no mundo exterior" (Davis, 1990, p.107-108). Mas, a despeito do fato de tais representações serem amplamente difundidas e implicarem um conjunto específico de papéis destinados às mulheres, os perfis e trajetórias abordados a seguir ilustram a existência de outras possibilidades, para elas, de inserção e de aquisição de prestígio. Antes de examinar os casos, arrolados em diferentes tipos de fontes, é relevante observar que, dada a natureza destas, muitas vezes não é possível acompanhar as histórias de vida de cada uma das suas protagonistas por longos períodos e analisá-las de modo mais circunstanciado. A isto associa-se a dificuldade, para quem se aventure a investigar o tema, de avaliar os efeitos sociais mais abrangentes da mobilidade local e muitas vezes efêmera de que tratamos aqui. No mais das vezes, pode-se apenas apresentar as informações que constam na documentação inquisitorial, em livros de fundação de conventos, em tratados voltados para a discussão de assuntos morais e vidas santas como um apanhado de evidências pontuais que sustentam o argumento de que certos tipos de performance religiosa constituíram uma via pela qual mulheres pertencentes aos setores subalternos adquiriram posições de relativo destaque nas suas comunidades.

\section{PeRformanCE Religiosa E Distinção SOCIAL}

Em trabalho voltado à discussão de estratégias de barbeiros e cirurgiões para ascender socialmente e obter privilégios por meio do ingresso e atuação nos quadros funcionais do Santo Ofício, Georgina Santos chama atenção para a relevância da documentação inquisitorial, para além do estudo das formas de crer e dos costumes, também no que toca à investigação de mecanismos de inclusão e ascensão social (Santos, 2011). ${ }^{4}$ Fontes produzidas pela Inquisição permitem explorar ainda outros tipos de mecanismos pelos quais certos indivíduos originalmente vinculados a setores subalternos ocuparam posições de algum destaque nas suas comunidades. As trajetórias inicialmente examinadas aqui são de mulheres acusadas, pelo Santo Ofício, dos crimes de molinosismo ${ }^{5}$ e de fingir êxtases, visões e revelações. Sua vivência religiosa está em geral associada a um grupo ou círculo, em particular a confessores ou diretores espirituais com os quais fizeram proposições consideradas heréticas pela ortodoxia católica e praticaram uma série de atos ligados à sexualidade, no interior de conventos e também fora deles. 
Essas condutas foram tratadas pelos inquisidores como vinculadas à doutrina que o teólogo aragonês Miguel de Molinos (1628-1696) desenvolveu em seus escritos, ou ao menos a sua defesa da licitude de atos carnais no processo inquisitorial instaurado contra ele (Molinos, 1977; Valente, 1974). No tocante ao erotismo, as proposições de Molinos que foram condenadas incluem a ideia de que Deus permite e deseja que o demônio violente os corpos de certos homens puros, cuja alma chegou a uma perfeita contemplação passiva, fazendo- os cometer atos carnais para humilhá-los e conduzi-los à verdadeira transformação. Nesse caso, tais ações não constituiriam pecado, pois não haveria consentimento (Hünermann; Hoffmann, 1996, p.543).

Pedro Vilas Boas Tavares faz abrangente revisão crítica das abordagens nos estudos sobre Molinos publicados até o momento em que escreveu seu livro sobre a penetração das ideias do teólogo em Portugal, interpretando suas concepções e conduta em relação às inquietações espirituais da cultura barroca (Tavares, 2005, esp. p.83-97). Particularmente com respeito aos processados por molinosismo, o autor conclui que a quase totalidade desses indivíduos não leu os textos de Molinos e que uns poucos teriam lido, ou ouvido referir, o conteúdo das 68 proposições consideradas por Roma como não conformes com a ortodoxia. Foram penitenciados como molinosistas "não porque, teologicamente, tenham aprendido de Molinos um sistema minimamente coerente de doutrina, mas porque um ou vários dos seus delitos encaixaram em algumas das proposições condenadas do teólogo aragonês”. Dessa forma, a maioria deles teria praticado "um gênero de 'molinismo' moral, com escassíssima componente doutrinal”. Tratar-se-ia de "factos hereticais', mas cometidos 'com ânimo lascivo"” (Tavares, 2005, esp. p.325-329).

Temos alguma resistência à interpretação das práticas relatadas nos processos predominantemente como condutas sexuais interditas, desvinculadas de significados religiosos, simples expressões de um "laxismo". Nesse sentido, a abordagem aqui proposta é consistente com a de William de Souza Martins. A partir do estudo do processo da beata Josefa do Sacramento, esse autor analisa, além de características do círculo do qual participavam as beatas e os padres penitenciados, dos usos do corpo e relações de gênero envolvidos, a "apropriação heterodoxa" da literatura mística, em especial do topos do "casamento místico", que fizeram. Para Martins, esses protagonistas se apropriaram de modelos devocionais derivados do Cântico dos Cânticos e da literatura mística por ele inspirada "a partir de uma ótica que não condenava o contato corporal, que colocava o corpo e o espírito no mesmo plano", para o que "foi 
decisiva a ação de um grupo de mulheres beatas da Ordem Terceira do Carmo" (Martins, 2015, esp. p.474).

As histórias das mulheres que nos interessam centralmente aqui emergem de um conjunto de processos que têm como rés, em sua maioria, pessoas residentes no norte de Portugal, em territórios pertencentes aos bispados de Viseu e do Porto. O universo dos réus inclui membros masculinos do clero que atuavam como confessores ou diretores de consciência, e suas filhas espirituais, muitas delas beatas. Os processos indicam a existência de redes de relações pelas quais eram transmitidos os fundamentos do que é referido nos interrogatórios e nas sentenças como "seita de Molinos". A "heresia" floresceu em grupos pertencentes ao clero secular, do qual 14 padres foram indiciados, e também em mosteiros masculinos como o dos capuchos de Viseu e em casas monásticas femininas. Suas concepções eram transmitidas entre indivíduos pertencentes a uma mesma comunidade ou a uma mesma família e incluíam, além dos "amorosos colóquios" com Deus, ideias como a do caminho da virtude e a da obediência ao confessor. Os depoimentos sugerem diferentes estágios de envolvimento, associados a diferentes estados de "abrazamento" do espírito, como o dom de lágrimas e "elevações” até Deus.

Um caso que se destaca em diversos documentos do Santo Ofício é o da beata Joana Maria de Jesus, qualificada como “Terceyra de certa Ordem”, que envergara a correia de Santo Agostinho e o cordão de São Francisco, penitenciada em 16 de junho de 1720 na igreja do Convento de São Domingos, em Lisboa, em auto da fé na presença de D. João V e de "muyta nobreza e povo”. Relatos sobre ela e sobre outros membros da sua família, assim como pessoas da comunidade a ela vinculadas na região de Viseu constam nos processos de sua irmã Úrsula Engrácia da Anunciação, também beata e acusada de fingir êxtases, além de molinosismo, ${ }^{6}$ e do seu irmão, o padre Manuel da Silva Santiago, bacharel em sagrados cânones, cônego de meia prebenda da Sé de Viseu, confessor e pregador. ${ }^{7} \mathrm{O}$ processo contra Joana, cuja existência e conteúdo são mencionados nos dos demais membros da sua família, parece ter-se perdido.

Embora muitas das evidências que constam no processo de Úrsula Engrácia a comprometessem de fato, referências aos comportamentos de Joana Maria ocupam lugar de igual ou maior destaque nos registros, o mesmo ocorrendo no processo do padre Manuel Santiago. Joana exercia indubitável liderança religiosa em seu meio. Diretores de consciência orientavam as pessoas a se aconselharem com ela, e eles próprios a procuravam para pedir conselhos em matéria de religião. As acusações contra ela, referida na lista de 
penitenciados no auto da fé como "abominavel Mestra dos escandalosos", evidenciam o importante papel de liderança que teve na região. Numa denúncia contra Joana, frei Simão da Soledade afirma que ela tinha "botado a perder" diversos clérigos com a sua doutrina. ${ }^{8}$

Os processos trazem diversos relatos de êxtases que Joana teria experimentado, tidos como expressão de sua santidade, em que ela parecia dormir, ou estar morta, mas em verdade estava "em prezença de Deos". Essas manifestações, com ela vestida de seda, sentada no meio de uma sala e rodeada por comitiva de outras beatas (referidas como "Duquezas, Condeças, Ayas, Camareiras e criadas"), sendo "apellidada por Raynha", provocariam choro coletivo nos presentes. ${ }^{9} \mathrm{O}$ padre Santiago relatou aos inquisidores que os fenômenos haviam se iniciado por ocasião da morte do seu pai, quando começou a ter "movimentos e abalos" em todo o corpo, doenças e "esquecimentos ... dos seus sentidos", sobretudo "quando ouvia falar em cousas de Deos". Seu médico teria concluído que era "couza extraordinária que so espiritualmente se devia tratar" ${ }^{10}$ Conforme declaração de sua irmã Úrsula Engrácia, em depoimento datado de 15 de abril de 1719, Joana tinha êxtases também nos cárceres do Santo Ofício. ${ }^{11}$

Ela sempre teria se mostrado disponível aos que a procuravam, fosse para executar tarefas como o cuidado dos doentes e a preparação de defuntos para o funeral, fosse para dar conselhos espirituais e "tirar [pessoas] do estado de culpa". São citados entre os que Joana havia resgatado do estado de culpa os padres Antonio dos Santos, Amaro de Almeida e Manoel da Cunha de Abranches, que antes teriam mantido "trato illicito" com mulheres. O resgate era feito por meio de exercícios espirituais, penitências e mortificações. Além disso, Joana praticava, com esses e diversos outros padres, "tocamentos" e "ações torpes", ditos sem pecado porque involuntários, sem intenção luxuriosa e feitos com o intuito de louvar a Deus. Muitas vezes essas práticas teriam resultado em êxtases, dela e dos próprios clérigos. ${ }^{12}$ Os depoimentos atestam que, desde pequena, Joana havia sido orientada por diretor espiritual e "guiada pella obediencia". ${ }^{13}$

Úrsula Engrácia também foi denunciada ao Santo Ofício com relatos de que tinha êxtases, principalmente ao ouvir cantarem em honra ao Menino Jesus, embora ela o tivesse negado nos interrogatórios. Confirmou que Deus lhe havia concedido o dom de lágrimas "para chorar os seus peccados, e os do proximo" e que tinha o mesmo dom meditando sobre a paixão e morte de Jesus Cristo. Foi, da mesma forma que a irmã, acusada de práticas de cunho sexual com clérigos, e de os aconselhar espiritualmente. Os interrogatórios a que foi 
submetida expressam as restrições da Igreja tridentina em relação à liderança religiosa feminina. Consta do seu processo que os inquisidores perguntaram a ela "se sabe ... que ás mulheres hé prohibido o officio de ensinar e aconcelhar ... aos sacerdotes, e com maior prohibição nas couzas sagradas...”. Sua sentença foi das mais duras, incluindo açoites públicos e degredo por 5 anos para Castro Marim. ${ }^{14}$ Sua irmã Joana também foi condenada a açoites, reclusão nos cárceres do Santo Ofício, degredo por 10 anos para a Ilha de São Tomé e "por toda a vida" dos bispados de Lamego e Viseu. ${ }^{15}$

Outra figura feminina tida pela comunidade como santa, com quem diretores espirituais se aconselhavam e orientavam suas filhas a se aconselharem foi Maria Lopes, natural e moradora em Casal das Donas, freguesia do Castelo de Penalva, bispado de Viseu. Maria, com 61 anos quando foi penitenciada na Igreja de São Domingos de Lisboa em 16 de junho de 1720, no mesmo auto da fé que a beata Joana Maria de Jesus, foi acusada e confessou inúmeras visões, incluindo descidas ao inferno, encontros com Jesus Cristo e revelações deste a ela. Seus depoimentos expressam as conotações eróticas dos delírios que relatava, estando estes via de regra relacionados ao erotismo praticado com seus confessores, com os quais obtinha consolação espiritual para as "grandes ânsias" que sentia, "abrazada" e "banhada em agoa com o fogo do amor Divino”. Por indicação do seu confessor, o padre Manoel de Almeida de Azevedo, Maria havia encontrado e se aconselhado com Joana Maria de Jesus. Diferentemente da maioria dos acusados de molinosismo, Maria era casada com o ferreiro Francisco Lopes, a única mulher casada entre todas as rés. ${ }^{16}$ Compartilhava a doutrina com sua filha, cujo nome era também Maria Lopes e que foi igualmente processada. ${ }^{17}$ Mas foi a mãe que, ao fim do julgamento, teve as penas mais duras. Considerada culpada de se fingir santa, "com muytas visoens, revelaçoens e favores extraordinarios de Deos", foi condenada a ser açoitada pelas ruas, a 10 anos de degredo na Ilha do Príncipe, ficando-lhe para sempre interdito entrar na diocese de Viseu. ${ }^{18}$

Seu caso ilustra muito adequadamente o vínculo entre performance religiosa e a aquisição de prestígio por indivíduos oriundos dos setores subalternos da sociedade, postulado por estudiosos do fenômeno (Crapanzano; Garrison, 1977, p.xi-xii; Lewis, 1989). Mulher pobre, que não sabia escrever, esposa de um ferreiro, pelos favores de Deus que afirmava ter, Maria era objeto de grande consideração e respeito por parte de certos confessores e da comunidade da Freguesia do Castelo de Penalva. O familiar do Santo Ofício que a conduziu para o cárcere registrou que, ao chegar à casa de Maria, a população dos arredores começou a gritar e a chorar "pella sua Sancta ... que os encaminhava 
pello caminho da virtude". Na ida para a prisão, ela teria lhe dito que, quando ia à Igreja do Castello de Penalva, "nam se podia valer com a gente, que se chegava a ella, e a procurava como mulher de virtude". ${ }^{19}$

Outro exemplo de aquisição de destaque por meio da performance religiosa é o de Teresa Maria de São José, "aliàs Madre Teresa”, terceira do Carmo, natural da Vila Ruiva, arcebispado de Évora, e moradora em Lisboa Ocidental. O carmelita descalço João de Santa Tereza, penitenciado pela Inquisição de Lisboa em 6 de julho de 1732, declarou que havia sido com ela que tinha aprendido o que depois praticava com sua filha espiritual, a beata Josefa do Sacramento, também terceira do Carmo. ${ }^{20}$ Teresa tinha 66 anos de idade quando da leitura da sentença, no mesmo auto da fé em que o frade e Josefa ouviram suas condenações. A dura pena a que foi condenada, por "culpas de molinismo" e fingimento de santidade - de açoites, reclusão a arbítrio nos cárceres do Santo Ofício e degredo de 10 anos para a Ilha de São Tomé - se deveu a fatos ocorridos ao longo da sua vida. Por largo período, desde os inícios da década de 1710, havia sido considerada santa, "hera procurada e consultada por várias pessoas que a tratavão espiritualmente", tendo desenvolvido planos de fundar um convento carmelita. Teve relato de sua vida escrito por seu diretor espiritual e foi retratada com hábito e véu branco, em um painel que seria colocado em lugar de honra no convento que intentava fundar. Com base na obra Nobiliarquia Trinitária, do Frei Manuel de Luzia (1766), Pedro Tavares afirma que, em Lisboa, "Madre Teresa" contava com "as attenções da maior parte da sua Nobreza e Fidalguia”, e faz menção a uma audiência particular que ela teria tido com o próprio rei d. João $\mathrm{V}$ para tratar de assuntos relativos à instalação do "seu" convento (Tavares, 2005, p.311-312).

As gazetas manuscritas da Biblioteca Pública de Évora documentam a mudança na fortuna de Teresa, com a divulgação das acusações de que era alvo e com sua condenação. O diário de 15 de julho de 1732 relata que "foi major o concurso para ver açoutar a Madre Thereza do que o do auto, o algoz a tratou com muito rigor, e o povo com muito mayor caindo algũas vezes". Inversamente, esses registros também evidenciam o favor de que ela antes desfrutava junto a membros das elites e populares. Outra passagem diz que, na leitura do auto, "se declarou no fim que hum ecleziastico de grande authoridade se mandava desdizer publicamente da boa conta em que a tiverá e se louvam muito as pessoas, que seguem este exemplo queimando publicamente as suas indignas riliquias" (Lisboa; Miranda; Olival, 2005, p.117-118). As gazetas indicam ainda o constrangimento coletivo que resultou do episódio (Lisboa; Miranda; Olival, 2005, p.222-223). 
Os autos da fé examinados por Pedro Tavares permitem o delineamento de um perfil social recorrente entre as penitenciadas por fingimento de santidade na segunda metade do século XVII e primeiras décadas do XVIII: mulheres solteiras, de idades relativamente avançadas e de extração social média ou baixa, seguramente do terceiro estado, como o atesta serem filhas de ferreiros, ourives, oleiros, sombreireiros e lavradores (Tavares, 2005, p.171-172; 188-191). A criação de um convento a partir da ação de beatas podia significar a realização máxima na vida religiosa de mulheres a quem tenham faltado condições para a entrada em um já existente.

Mas a conventualização de beatérios ou os esforços para controlar o estilo de vida de mulheres consideradas beatas podiam significar uma tentativa de interferir em comportamentos que, de certo ponto de vista, parecessem excessivamente relaxados. Assim, um Domingo Peres, mantenedor de um recolhimento no Postigo de Santo António do Campo da Vinha, em Braga, exigia que as candidatas às seis vagas ali disponíveis passassem por diligências de vita et moribus e de limpeza de sangue, além de se conformarem a uma disciplina que exigia a guarda de clausura (Tavares, 2005, p.143-148). No Convento de Nossa Senhora da Esperança de Vila Viçosa, fundado a partir de um recolhimento, as progressivas tentativas de reforma na vida das religiosas chegou ao ponto da ruptura e da apostasia. Três das fundadoras, irmãs, que acompanharam Isabel Cheirinha desde o início e aceitaram se submeter às vontades reformadoras da duquesa de Bragança, terminaram, após anos de inquietações e cismas, por romper os votos e se recolher novamente "em casa honesta e religiosa de algũa pessoa vertuosa”. Um dos nós da discórdia, a fiar no livro que conta a fundação do convento, escrito em 1657 por uma de suas religiosas, recaía na dura pobreza exigida pela nova regra de vida, que as três nunca quiseram "entender, nẽ conhecer". Outro, no da guarda da clausura. Segundo o relato, as dissidentes "hiaõ para fora quando e como queriaõ" e "falavaõ a portas abertas cõ os seculaes q ẽtravaõ dentro do convto", recusando-se reiteradamente a interromper o costume (Baptista, 1657, fl. 12-15v).

O caminho de vida beata, nem sempre alternativa resignada a um claustro inalcançável, tinha suas especificidades e vantagens. Uma dessas era a relativa liberdade criada pela indefinição de seu estatuto social. Inocência, personagem da Peregrinaçam cristam indecisa quanto a que rumo seguir mas certa de sua opção por uma vida casta, expõe o dilema daquelas desprovidas de recursos: "pera freira tem os mosteiros os dotes tão levantados que não chega là minha possibilidade, pelo que me quisera recolher com hũa dessas verdadeiras beatas”. O obstáculo era, na opinião de Quintiliano, um de seus aconselhadores, 
achar quem merecesse ser assim chamada. Segundo ele, havia muitas que se faziam de beatas para evitar constrangimentos, gozando de liberdade e desconhecendo os tipos de sujeição a que eram submetidas donzelas, solteiras, casadas, freiras ou viúvas. Outro aconselhador de Inocência, Aurélio, afirma que as impostoras eram tão habilidosas que se tornava virtualmente impossível distingui-las das verdadeiras: "as que não saõ sabẽse melhor fingir que um comediante". Um meio de identificá-las, além da afetação e do alarde em seus comportamentos, consistia em checar se mantinham frugalidade no comer. Caso fossem chegadas a manjares "preciosos", "com que a sustentaõ molheres ricas por rezar por ellas”, o melhor a fazer seria manter distância (Carvalho, 1620, fls. 133-136v).

Testemunhos como esse demonstram preocupação com o costume de receber essas mulheres e apreciar sua companhia e convivência. Ao mesmo tempo, também sugerem ser essa uma rota relativamente comum para a aquisição de prestígio e rendas por mulheres de baixa extração. Isso poderia se dar de maneira assumidamente criminosa, a exemplo das "unhas bentas", "que lançando bençãos, e apoyando virtudes, e clamando misericordias, e amores de Deos, purgaõ as bolças, que encontraõ" (Costa, 1744[?], p.251-257). ${ }^{21}$ Mas também podiam ser consideradas como decorrência da condição frágil da mulher e, mais especificamente, da mulher pobre. Por esse caminho vai um testemunho condescendente proferido por uma "señora discreta" e recolhido por Antonio Arbiol. Para aquela, todas as criaturas desejavam naturalmente ser estimadas e ter sua sobrevivência assegurada. Aos homens, diversos caminhos eram oferecidos para esse cumprimento: armas, ciências, santidade. Às mulheres, em sua opinião naturalmente "vanas, y amigas de que nos alaben", as perspectivas se revelavam bem mais estreitas. As nobres, que já gozavam de “conveniencia, y estimacion", não as buscavam por meio de artifícios e invenções. Já as "pobres, ordinarias y comunes", vendo-se tidas "por virtuosas, y santas" e que "todos las alaban y les dàn quanto han de menester para la conveniencia de su vida, las engaña facilmente por este camino el Demonio". Essa era a explicação, arrematava, para o fato de as mulheres de "baxa esfera" serem maioria nos autos da fé, "mas que de las ricas, y nobles".

Arbiol parece concordar, no geral, com essa opinião. Como ele diz, a experiência lhe teria mostrado como muitas "personas espirituales" optavam pelo "oficio de la virtud para vivir sin trabajar", "andando todo el dia de casa en casa, sin cesar de hablar, haziendo ceremonias". No entanto, para tornar o parecer da "senhora discreta" mais acertado, Arbiol sugere que as mulheres das elites deveriam reconhecer sua parcela de responsabilidade na criação desse 
estado de coisas. As "Señoras ricas, y autorizadas" eram, para ele, causa da perdição daquelas outras, de baixa esfera, ao colocá-las em situação de risco perguntando-lhes "lo que no les conviene saber": "si el marido se salvò, ò se condenò; y si pariràn hijo, ò hija; si estàn en gracia, ò en peccado, y otros desvarios semejantes, y aun otras simplicidades mas ridiculas". Balizando sua opinião moralizante com uma visão ampliada do fenômeno, Arbiol nota as contradições nos chistes que rebaixavam as penitenciadas: "lo que resulta de esto es, que corriendo el tiempo castigan, y afrentan à la Beata, y la Señora se queda riẽdo de sus embustes, sin hazer-se conciencia, ni formar escrupulo de que ella la puso en la ocasion de su ruìna" (Arbiol, 1706, p.78-84).

Caberia ainda adicionar outras reflexões sobre as desigualdades de foco e alcance da máquina punitiva, quando a matéria era controlar comportamentos de mulheres de alta ou baixa condição. José Pedro Paiva, em estudo sobre Arcângela do Sacramento, acusada por fingimento de santidade e suspeita de enveredar pelos "erros de Molinos", sugere que a punição de mulheres pobres traduzia, numa lógica perversa, o "equilíbrio muito instável” entre o discurso e a prática das autoridades eclesiásticas. Se, por um lado, pregava-se aos fiéis o caminho da santidade e "apelava-se à perfeição de comportamentos com base no modelo de vida dos santos", por outro, "quando particularmente 'os rústicos' e as mulheres afirmavam ter seguido essa via e terem protagonizado experiências idênticas às dos santos, eram acusados de tentados ou ilusos do diabo, ou de fingidores" (Paiva, 2000).

Mas não só das vidas de santos essas mulheres retiravam exemplos que lhes serviam de orientação e modelos a mimetizar. Muitas outras, de condição semelhante às delas, haviam pavimentado um caminho socialmente reconhecido, deixando um legado de respeito e veneração que ao mesmo tempo conservava seus nomes para a posteridade. Na contramão do que os registros do Santo Ofício deixam ver, uma multitude de crônicas religiosas e coleções de registros de vidas virtuosas aponta para o caminho bem singrado da perfeição.

Esse é o caso, por exemplo, do espaço concedido às mulheres simples por fr. Luis dos Anjos em seu Jardim de Portugal, obra dedicada a divulgar os exemplos de "molheres excellentes em todo genero de virtudes" que o reino português já havia produzido. Ainda que a atenção recaísse fundamentalmente sobre monjas - a maioria de extração nobre - e santas portuguesas assim reconhecidas ou de culto imemorial, o cronista agostinho encontrou espaço para, aqui e ali, transmitir os exemplos daquelas "mais humildes ervinhas que nacẽ em os mais desabridos, e inhabitados vales”. Nessa categoria se enquadrava 
Caterina da Luz, pobre moradora de Cós, no bispado de Leiria, a quem repetidas vezes a Virgem apareceu quando trabalhava nos campos. Numa dessas ocasiões, a ela foi mostrada uma fonte de águas curativas e pedido que a revelasse aos moradores da terra. Comprovadas as propriedades dos banhos pelo próprio bispo, Caterina passou a banhar enfermos no local e, considerada "molher muy virtuosa", a receber frequentes e largas esmolas que, decidida a não "ser mais rica que de antes", destinava aos pobres. Estimada em vida, Caterina também ganhou uma sepultura no altar-mor de uma igreja construída posteriormente no mesmo local (Anjos, 1626, p.497-499).

Em Olivença, Jorge Cardoso dizia estar guardada viva a lembrança de Maria da Cruz, "fervorosa amante de Jesus". Essa terceira da Ordem da Penitência, "filha de paes humildes, mas mui virtuosos", conheceu em vida a fama pública de santidade, angariando a atenção do "povo" pelos "notaveis raptos", "que lhe duravaõ tam cheos de superabundantes consolações". Morta em 1635, "acudio ao mosteiro de S. Francisco grande concurso de gente, onde depois de lhe beijarem pès, \& maõs com veneração como pessoa sancta, \& cortarem do habito com grande fé por reliquias, se lhe deu honorifica sepultura" (Cardoso, 1652, tomo I, p.4-5; 10).

Já Leonor Rodrigues, tecedeira cuja roca fiou a sobrevivência de seis irmãs e do pai viúvo e doente, era conhecida por manter colóquios frequentes com santos da Igreja e com almas do Purgatório, por suas habilidades proféticas e por ser capaz de enxergar "o intrinseco das pessoas", declarando-lhes "o bom, ou mao estado em que andavão" e fazendo-os conhecer o "que cada hũa tinha de passar ... para que emendassem as vidas". Segundo o relato de Cardoso, Leonor sofreu perseguições e contrariedades, mas isso não parece ter afetado sua posição. "Buscada, \& respeitada de muita gente nobre, \& plebea”, Leonor também gozaria de prestígio junto aos "Grandes da Corte" (Cardoso, 1657, tomo II, p.515-517; 521). O autor sugere que essa terceira carmelita figurava entre as pessoas que vaticinaram a Restauração de 1640, identificando-a como a pessoa de que fala a Restauração de Portugal Prodigiosa no capítulo "das cousas que certa pessoa disse vira sobre Portugal ter cedo Rey Portuguez”. Ali, afirma-se que em Évora viveu mulher com fama de virtuosa, ligada à Ordem Terceira dos Carmelitas e que gozava de proximidade com a casa do Marquês de Ferreira. Seu prestígio chegava ao ponto de homens da cidade, recrutados para a armada do Conde da Torre que ia ao Brasil, pedirem-lhe que os encomendasse a Deus, ocasião em que ela anteviu, em meio a lágrimas, o mau sucesso da jornada. 
Saberíamos ainda por relatos do Marquês de Ferreira que ela, durante o levantamento de Évora de 1637, disse-lhe: "quanto este levantamento cedo se acabará, porem outro virá, que não acabará”. Disse-lhe também, em outra ocasião, que "em Portugal via Rey Portuguez", sem confirmar as suspeitas do marquês de que se tratava do Duque de Bragança. A fama e as profecias de Leonor iam longe, já que "estas cousas communicava o Marquez a Sua Magestade, com muitas outras, que esta serva de Deos lhe descobria" (Almeida, 1643, p.158-163).

O reconhecimento social de que desfrutava Leonor Rodrigues, assim como várias das demais mulheres cujas trajetórias foram exploradas neste artigo, guarda certa homologia com os mecanismos costumeiros de legitimação da reputação e excelência da "gente melhor e de mayor qualidade" no contexto ibérico moderno (Cf. Guillén Berrendero, 2011, passim). Um desses mecanismos é a valorização da memória das virtudes e feitos do indivíduo e/ou de sua família. A vida de Teresa Maria de São José foi registrada em livro por seu diretor espiritual. Mesmo as que não contaram com tal deferência tiveram sua fama divulgada em círculos por vezes bastante alargados. Entre os exemplos de reputação pública de valor aqui examinados destaca-se o de Maria Lopes, conforme observou o próprio familiar do Santo Ofício encarregado de levá-la para o cárcere. $\mathrm{O}$ conjunto de representações em que se assentava o prestígio social incluía também o testemunho de pessoas "de crédito \& confiança" a propósito da distinção de certas figuras, mecanismo que encontra paralelos na menção ao médico que teria examinado a beata Joana Maria, em Viseu, atestando que seus êxtases constituíam fenômeno espiritual extraordinário, e nos depoimentos favoráveis de seu irmão, o padre Manuel da Silva Santiago, que gozava de boa posição eclesial antes da condenação. Por fim, também compunha o rol dos elementos que conferiam distinção a apreciação do indivíduo por grupos de prestígio, a exemplo da nobreza titulada ou dos que haviam ascendido às elites pelo exercício de altas funções, e o convívio com membros desses grupos, aspectos ilustrados muito especialmente pelos casos da Madre Teresa e de Leonor Rodrigues.

Fazendo uso de táticas e competências centralmente relacionadas à performance religiosa, essas mulheres constituíram para si um cabedal de honra que, ao menos por determinado tempo no caso das que acabaram sentenciadas, lhes permitiu ocuparem espaços de expressão no Portugal dos séculos XVII e XVIII. 


\section{REFERÊNCIAS}

\section{Fontes impressas}

ALMEIDA, Gregorio de. Restauração de Portugal Prodigiosa. Lisboa: por Antonio Alvarez, 1643.

ANDRADE, Diogo de Paiva de. Casamento perfeito em que se contem advertencias muito importantes pera viverem os casados em quitação, \& contentamento. Lisboa: por Jorge Rodriguez, 1630.

ANJOS, Luis dos. Jardim de Portugal, em que se da noticia de algũas Sanctas, \& outras molheres illustres em virtude, as quais nascerão, ou viverão, ou estão sepultadas neste Reino, e suas cõquistas. Coimbra: em casa de Nicolao Carvalho, 1626.

ARBIOL, Antonio. Desengaños Misticos a las almas detenidas, o engañadas en el camino de la Perfeccion. Saragoça: por Manuel Roman, 1706.

BAPTISTA, Antonia do. Livro da fundação do Santo Convento de Nossa Senhora da Esperança de Vila Viçosa. Vila Viçosa, Mss., 1657.

BARROS, João de. Espelho de Casados. Porto: Vasco Diaz Tanco de Frexenal, 1540.

CARDOSO, Jorge. Agiologio Lusitano dos sanctos, e varoens illustres em virtude do Reino de Portugal, e suas conquistas. Tomo I. Lisboa: na Officina Craesbeekiana, 1652.

Agiologio Lusitano dos sanctos, e varoens illustres em virtude do Reino de Portugal, e suas conquistas. Tomo II. Lisboa: na Officina de Henrique Valente D’Oliveira, 1657.

CARVALHO, Tristão Barbosa de. Peregrinaçam cristam. Lisboa: por Geraldo da Vinha, 1620.

COSTA, Manuel da (atribuído a). Arte de furtar, espelho de enganos, theatro de verdades, mostrador de horas minguadas, gazua geral dos Reynos de Portugal. Amsterdam[?]: na officina de Martinho Schagen[?], 1744[?].

LEÃO, Duarte Nunes de. Descripção do Reino de Portugal. Lisboa: por Jorge Rodrigues, 1610.

MELO, Francisco Manuel de. Carta de guia de casados [como visto em FERNANDES, Maria de Lurdes Correia (edição, introdução e notas). Porto: Campo das Letras, 2003]. Lisboa: na Officina Craesbecckiana, 1651.

MIRANDA, Martim Afonso de. Tempo de agora em dialogos. Lisboa: por Pedro Craesbeeck, 1622.

MOLINOS, Miguel de. Guia Espiritual. Edicion preparada por Santiago González Noriega. Madrid: Ed. Nacional, 1977.

NAVARRO, Gaspar. Tribunal de superstición ladina. Huesca: por Pedro Bluson, 1631.

VIVES, Juan Luis. Instructió dla muger christiana: dondese contiene como se ha de criar una dózella hasta casarla: y despues de casada como ha de regir su casa y bivir 
bienavẽturadamẽte cõ su marido. y si fuere biuda lo q deve de hazer. Zamora: por Pedro Louans, 1539.

\section{Estudos}

BOXER, Charles R. A mulher na expansão ultramarina ibérica: 1415-1815. Lisboa: Livros Horizonte, 1977.

CASTILLO GÓMEZ, Antonio. La pluma de Dios: María de Ágreda y la escritura autorizada. Via Spiritus, n.6, p.103-119, 1999.

. Entre la pluma y la pared: una historia social de la escritura en los Siglos de Oro. Madrid: Akal, 2006.

CRAPANZANO, Vincent; GARRISON, Vivian (Ed.) Case Studies in Spirit Possession. New York \& London: John Wiley \& Sons, 1977.

CURTO, Diogo Ramada. O discurso político em Portugal (1600-1650). Lisboa: Projecto Universidade Aberta, 1988.

DAVIS, Natalie Zemon. Culturas do povo: sociedade e cultura no início da França moderna. Rio de Janeiro: Paz e Terra, 1990.

. Nas margens: três mulheres do século XVII. São Paulo: Companhia das Letras, 1997.

DURÃES, Andreia. Grupos intermédios em Portugal (1600-1850): uma aproximação ao vocabulário social. Topoi, Rio de Janeiro: PPGH-UFRJ, v.14, n.27, p.318-343, jul./dez. 2013.

EVANGELISTI, Silvia. Nuns: A History of Convent Life 1450-1700. Oxford: Oxford University Press, 2007.

FEITLER, Bruno. Hierarquias e mobilidade na carreira inquisitorial portuguesa: a centralidade do tribunal de Lisboa. In: MONTEIRO, Rodrigo Bentes; FEITLER, Bruno; CALAINHO, Daniela; FLORES, Jorge (Org.) Raízes do privilégio: mobilidade social no mundo ibérico do Antigo Regime. Rio de Janeiro: Civilização Brasileira, 2011. p.235-258.

FERNANDES, Maria de Lurdes Correia. Espelhos, cartas e guias: casamento e espiritualidade na Península Ibérica. 1450-1700. Porto: Instituto de Cultura Portuguesa - Faculdade de Letras da Universidade do Porto, 1995.

Ausência do marido e 'des-governo' da casa na época dos descobrimentos. Algumas imagens da literatura e da tratadística moral ibérica. Cadernos Históricos (Separata), Porto, v.VII, p.79-93, 1996.

FONSECA, Fernando Taveira da. Notas acerca do pensamento religioso sobre a mulher. In: A MULHER na sociedade portuguesa. Actas do Colóquio (Separata). Coimbra, 20 a 22 mar. 1985. Coimbra: Coimbra Ed., 1986. p.5-24.

GUILLÉN BERRENDERO, José Antonio. Gente melhor \& de mayor qualidade: algumas reflexões sobre a ideia de prestígio e seus agentes em Castela e Portugal 
1556-1640. In: MARTÍNEZ HERNÁNDEZ, Santiago (Dir.) Governo, política e representaçães do poder no Portugal dos Habsburgo e nos territórios ultramarinos (1581-1640). Lisboa: CHAM/UNL/Universidade dos Açores, 2011. p.45-68.

HESPANHA, António Manuel. Governo, elites e competência social: sugestões para um entendimento renovado da história das elites. In: BICALHO, Maria Fernanda; FERLINI, Vera Lúcia Amaral (Org.) Modos de governar: idéias e práticas políticas no Império português. São Paulo: Alameda, 2005. p.39-44.

HÜNERMANN, Peter; HOFFMANN, Joseph (Ed.) Symboles et Définitions de la Foi Catholique. Paris: Les Éditions du Cerf, 1996.

KING, Margareth. Women of the Renaissance. Chicago: University of Chicago Press, 1991.

LEWIS, Ioan M. Ecstatic religion: a study of shamanism and spirit possession. London \& New York: Routledge, 1989.

LISBOA, João Luís; MIRANDA, Tiago C. P. dos Reis; OLIVAL, Fernanda (Ed.) Gazetas manuscritas da Biblioteca Pública de Évora. v.2 (1732-1734). Lisboa: Edições Colibri, CHC-UNL e CIDEHUS-UE, 2005.

MALENA, Adelisa. Molinos, Miguel de. In: PROSPERI, Adriano. Dizionario Storico dell'Inquisizione. v.2. Pisa: Edizioni della Normale, 2010. p.1059-1060.

MARTINS, William de Souza. O casamento espiritual da beata Josefa do Sacramento: Análise de um processo inquisitorial do século XVIII. Varia historia, Belo Horizonte: PPGH-UFMG, v.31, n.56, p.451-478, ago. 2015.

MONTEIRO, Nuno Gonçalo. Poder senhorial, estatuto nobiliárquico e aristocracia. In: MATTOSO, José; HESPANHA, António Manuel (Dir.) História de Portugal: o Antigo Regime. v.IV. Lisboa: Estampa, 1998. p.333-379.

PAIVA, José Pedro. Missões, directores de consciência, exercícios espirituais e simulações de santidade: o caso de Arcângela do Sacramento (1697-1701). Gaudela, Gouveia: Câmara Municipal de Gouveia, n.1, p.3-28, 2000.

SALES SOUZA, Evergton. Disputa De auxiliis. In: PROSPERI, Adriano. Dizionario Storico dell'Inquisizione. v.1. Pisa: Edizioni della Normale, 2010. p.496-497.

SANTOS, Georgina Silva dos. Artes e manhas: estratégias de ascenção social de barbeiros, cirurgiões e médicos da Inquisição portuguesa (séculos XVI-XVIII). In: MONTEIRO, Rodrigo Bentes; FEITLER, Bruno; CALAINHO, Daniela; FLORES, Jorge (Org.) Raízes do privilégio: mobilidade social no mundo ibérico do Antigo Regime. Rio de Janeiro: Civilização Brasileira, 2011. p.259-282.

TAVARES, Pedro Vilas Boas. Beatas, inquisidores e teólogos: reacção portuguesa a Miguel de Molinos. Porto: Centro Inter-universitário de história da espiritualidade, 2005.

VALENTE, Jose Angel. Ensayo sobre Miguel de Molinos e Miguel de Molinos, Guia espiritual seguida de la Defesa de la contemplacion por vez primera impresa. Barcelona: Barral, 1974. 
VELOSO, Carlos José Rodarte de Almeida. Imagem e condição da mulher na obra de autores portugueses da $1^{\text {a }}$ metade do séc. XVII. In: A MULHER na sociedade portuguesa. Visão histórica e perspectivas actuais. Actas do Colóquio, v.II. Coimbra, 20 a 22 mar. 1985. Coimbra: Coimbra Ed., 1986. p.251-270.

\section{NOTAS}

${ }^{1}$ Lígia Bellini é Bolsista de Produtividade em Pesquisa, CNPq. Moreno Pacheco, quando da redação deste artigo, era pesquisador PNPD/Capes no Programa de Pós-Graduação em História da UFBA.

${ }^{2}$ Ver a este respeito, sobretudo, FERNANDES, 1995.

${ }^{3}$ Para essa contextualização, remetemos aos estudos citados nesta seção, em especial a FERNANDES, 1995.

${ }^{4}$ Formas de mobilidade e inserção nas altas hierarquias do Santo Ofício também foram estudadas a partir de documentos dessa instituição (FEITLER, 2011).

${ }^{5}$ Este crime é também referido, nas fontes, como molinismo. Mas atualmente, nos estudos que tratam de religião e religiosidade no período moderno, o termo molinismo em geral designa a doutrina do jesuíta espanhol Luis de Molina (1535-1600) sobre o livre-arbítrio e a predestinação. Ver MALENA, 2010, p.1060 e SALES SOUZA, 2010, p.497.

${ }^{6}$ Arquivo Nacional da Torre do Tombo, doravante ANTT, Inquisição de Coimbra, processo n. 8936 .

${ }^{7}$ ANTT, Inquisição de Coimbra, processo n. 3351. Cf. também "Lista das Pessoas que sahiram, condenaçoens que tiveram, \& sentenças que se leram no Auto publico da Fé, que se celebrou na Igreja do Convento de S. Domingos desta Cidade de Lisboa Occidental, em Domingo 16 de Junho de 1720", reproduzida em TAVARES, 2005, Apêndice V.

${ }^{8}$ ANTT, Inquisição de Coimbra, processo n. 3351, fl. 104.

${ }^{9}$ ANTT, Inquisição de Coimbra, processo n. 3351, fls. 54 e 59.

${ }^{10}$ ANTT, Inquisição de Coimbra, processo n. 3351, fl. 120.

${ }^{11}$ ANTT, Inquisição de Coimbra, processo n. 8936.

${ }^{12}$ ANTT, Inquisição de Coimbra, processos n. 8936 e 3351, passim.

${ }^{13}$ ANTT, Inquisição de Coimbra, processo n. 3351, fl. 122.

${ }^{14}$ ANTT, Inquisição de Coimbra, processo n. 8936.

15 "Lista das Pessoas que sahiram, condenaçoens que tiveram, \& sentenças que se leram no Auto publico da Fé, que se celebrou na Igreja do Convento de S. Domingos desta Cidade de Lisboa Occidental, em Domingo 16 de Junho de 1720", reproduzida em TAVARES, 2005, Apêndice V. 
${ }^{16}$ ANTT, Inquisição de Coimbra, processo n. 10012. Cf. também TAVARES, 2005, p.190191.

${ }^{17}$ ANTT, Inquisição de Coimbra, processo n. 1775.

${ }^{18}$ ANTT, Inquisição de Coimbra, processo n. 10012, fls. 216-217.

${ }^{19}$ ANTT, Inquisição de Coimbra, processo n. 10012, fls. 15v e 16v.

${ }^{20}$ ANTT, Inquisição de Lisboa, processos n. 2287, fls. 135v-136, e 2288, fls. 19v e seguintes. (A paginação recomeça a partir do exame do carmelita). O processo de Madre Theresa foi extraviado. Algumas das informações sobre ela aqui apresentadas constam em TAVARES (2005, p.310ss). Esse autor consultou parte disponível do processo, à qual não tivemos acesso.

${ }^{21}$ Autoria, lugar, ano e oficina de impressão são incertos.

Artigo recebido em 23 de março de 2017. Aprovado em 19 de setembro de 2017. 